\title{
DYNAMIC CHARACTERISTICS OF A THIN FILM OPTOELECTRONIC MEMORY SYSTEM
}

\author{
Z. PORADA \\ Institute of Electrical Engineering, Technical University, Warszawska 24, 31-155 Kraków (Poland)
}

E. SCHABOWSKA-OSIOWSKA

Department of Electronics, Academy of Mining and Metallurgy, Al, Mickiewicza 30, 30-059 Kraków (Poland)

(Received July 7, 1995; in final form September 1, 1995)

\section{INTRODUCTION}

Among more and more numerous publications devoted to various kinds of optoelectronic systems, a number of articles describing systems with photoconductive (PC) and electroluminescent (EL) elements can be found ${ }^{1-4}$.

Thin film electroluminescent cells and photoconducting elements with optical feedback are interesting because of their possible application in optoelectronic memory systems.

In its simplest form, the PC-EL system is obtained by series connection of a photoconducting element with an electroluminescent cell. This system is supplied with a sinusoidal voltage with fixed amplitude and frequency. The input signal is in the shape of rectangular light pulses illuminating the PC element, and the output signal is the luminance of the light emitted from the EL cell. Part of the output signal is directed to the input, and thus an optical feedback is produced in the system.

For sufficiently high values of feedback coefficient, the PC-EL system is bi-stable in character ${ }^{5,6}$. Simple, two-element PC-EL systems with optical feedback can be used, for example, in optoelectronic memory systems.

A diagram of an optoelectronic memory system is presented in Fig. 1. When the photoconducting element $\mathrm{PC}_{1}$ is illuminated with a light pulse, the voltage drop on the element is low and almost all the voltage $U$ is applied to the electroluminescent cell $\mathrm{EL}_{1}$, causing light emission. Owing to the optical feedback, the $\mathrm{EL}_{1}$ cell illuminates the element $\mathrm{PC}_{1}$, so that the $\mathrm{PC}_{1}-\mathrm{EL}_{1}$ system is in the on state. The $\mathrm{PC}_{2}-\mathrm{EL}_{2}$ system is in the off state and does not emit light until the element $\mathrm{PC}_{2}$ is illuminated. Then the electroluminescent cell $\mathrm{EL}_{2}$ emits light and thereby indicates that the $\mathrm{PC}_{1}-\mathrm{EL}_{1}$ system is in the on state. When the $\mathrm{EL}_{1}$ cell is not emitting light, despite illumination of the element $\mathrm{PC}_{2}$, there is no output pulse from the cell $\mathrm{EL}_{2}$. The $\mathrm{PC}_{1}-\mathrm{EL}_{1}$ system is then in the off state. 


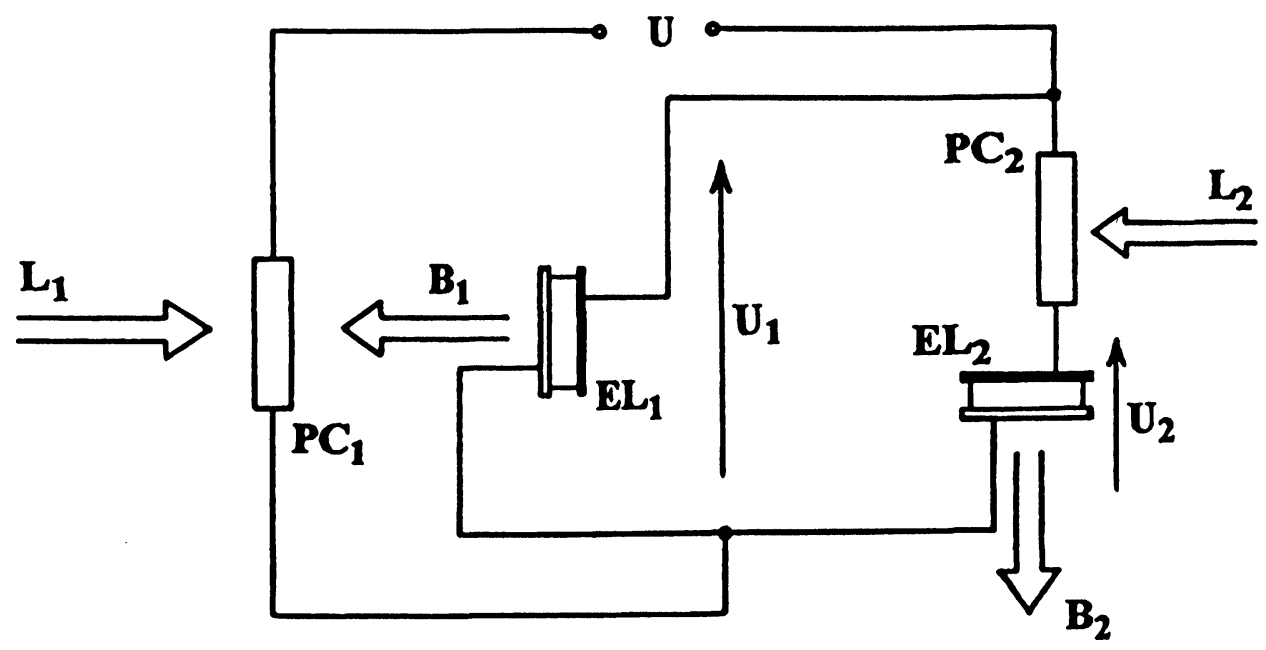

FIGURE 1 Diagram of an optoelectronic memory system.

\section{THEORETICAL MODEL}

A theoretical model suitable for analyzing the dynamic characteristics of a thin film optoelectronic memory system is proposed using the circuit shown in Fig. 1.

PC-EL memory systems are supplied with an alternating sinusoidal voltage:

$U=U_{0} \sin (\omega t+\varphi)$

where $\mathrm{U}_{0}$ is the amplitude, $\omega$ is the angular frequency, and $\varphi$ is the initial phase.

The instantaneous value of voltage $U_{1}$ on the electroluminescent cell $\mathrm{EL}_{1}$ can be described by the equation:

$\frac{d}{d t} U_{1}=\frac{1}{C_{E L 1}}\left[\left(U-U_{1}\right)\left(G_{01}+G_{1}\right)-\left(U_{1}-U_{2}\right)\left(G_{02}+G_{2}\right)\right]$

where $\mathrm{C}_{\mathrm{EL} 1}$ is the capacitance of the $\mathrm{EL}_{1}$ cell, $\mathrm{G}_{01}$ is the "dark" conductance of the $P_{1}$ photoconductive element, $G_{1}$ is the instantaneous value of the conductance of the $P C_{1}$ element, $G_{02}$ and $G_{2}$ are the "dark" conductance and instantaneous value of the conductance of the $\mathrm{PC}_{2}$ element, respectively, and $\mathrm{U}_{2}$ is the instantaneous value of voltage on the $\mathrm{EL}_{2}$ cell.

The instantaneous value of conductance $G_{1}$ can be expressed by the equation ${ }^{7}$ :

$\frac{d}{d t} G_{1}=a_{1}\left(L_{1}+\beta B_{1}\right)-\frac{G_{1}}{L_{1}}$

where $L_{1}$ is the instantaneous value of external illumination of the $\mathrm{PC}_{1}$ element (input signal), $B_{1}$ is the instantaneous value of the luminance $B_{1}$ emitted by the $\mathrm{EL}_{1}$ cell, $\beta$ is the optical feedback coefficient of the $P_{1}$ element with the $E L_{1}$ cell, $a_{1}$ is a constant parameter for the given $\mathrm{PC}_{1}$ element and $\tau_{1}$ is the photoconductivity rise time for this element. 
The luminance $B_{1}$ can be expressed by the formula given by Alfrey and Taylor ${ }^{8}$ :

$B_{1}=B_{01} \exp \left(-\gamma_{1} t\right) \exp \left(\frac{-b_{1}}{\sqrt{\left|U_{1}\right|}}\right)$

where $B_{01}, \gamma_{1}$, and $b_{1}$ are constant parameters for given a $E L_{1}$ electroluminescent cell.

The instantaneous value of voltage $\mathrm{U}_{2}$ on the $\mathrm{EL}_{2}$ electroluminescent cell can be described by the equation:

$\frac{d}{d t} U_{2}=\frac{1}{C_{E L 2}}\left[\left(U_{1}-U_{2}\right)\left(G_{02}+G_{2}\right)\right]$

where $\mathrm{C}_{\mathrm{EL} 2}$ is the capacitance of $\mathrm{EL}_{2}$.

The instantaneous value of conductance $\mathrm{G}_{2}$ of the $\mathrm{PC}_{2}$ element can be expressed by the equation:

$\frac{d}{d t} G_{2}=a_{2} L_{2}-\frac{G_{2}}{\tau_{2}}$

where $\mathrm{L}_{2}$ is the instantaneous value of external illumination of the $\mathrm{PC}_{2}$ element (input signal), $\mathrm{a}_{2}$ is a constant parameter for the given $\mathrm{PC}_{2}$ element, and $\tau_{2}$ is the photoconductivity rise time for this element.

The input signal in the shape of luminance $B_{2}$ of the light emitted by the $\mathrm{EL}_{2}$ electroluminescent cell can be expressed also by the formula given by Alfrey and Taylor:

$B_{2}=B_{02} \exp \left(-\gamma_{2} t\right) \exp \left(\frac{-b_{2}}{\sqrt{\left|U_{2}\right|}}\right)$

where $B_{02}, \gamma_{2}$, and $b_{2}$ are constant parameters for given $E L_{2}$ cell.

Solving the set of equation (1)-(7) one can calculate the dynamic characteristics of a memory system containing PC and EL elements.

\section{EXPERIMENTAL DETAILS AND RESULTS}

A thin film PC-EL optoelectronic memory element was made by vacuum evaporating photoconductive and electroluminescent layers. The photoconductive element (Fig. 2) was prepared as a sandwich-type system on a Corning 7059 glass substrate.

The first layer was a transparent electrode of tin-doped $\operatorname{In}_{2} \mathrm{O}_{3}$, obtained by the reactive cathode sputtering of $90 \%$ In- $10 \% \mathrm{Sn}$ alloy. The second layer was a photoconductive $\mathrm{CdS}$ film $^{9}$ doped with copper and chlorine and evaporated under vacuum at a pressure $6.7 \times 10^{-3} \mathrm{~Pa}$.

The electroluminescent cell (Fig. 2), was a thin film capacitor with an average thickness of $0.85 \mu \mathrm{m}$ produced by the vacuum evaporation of copper-, chlorine- and 


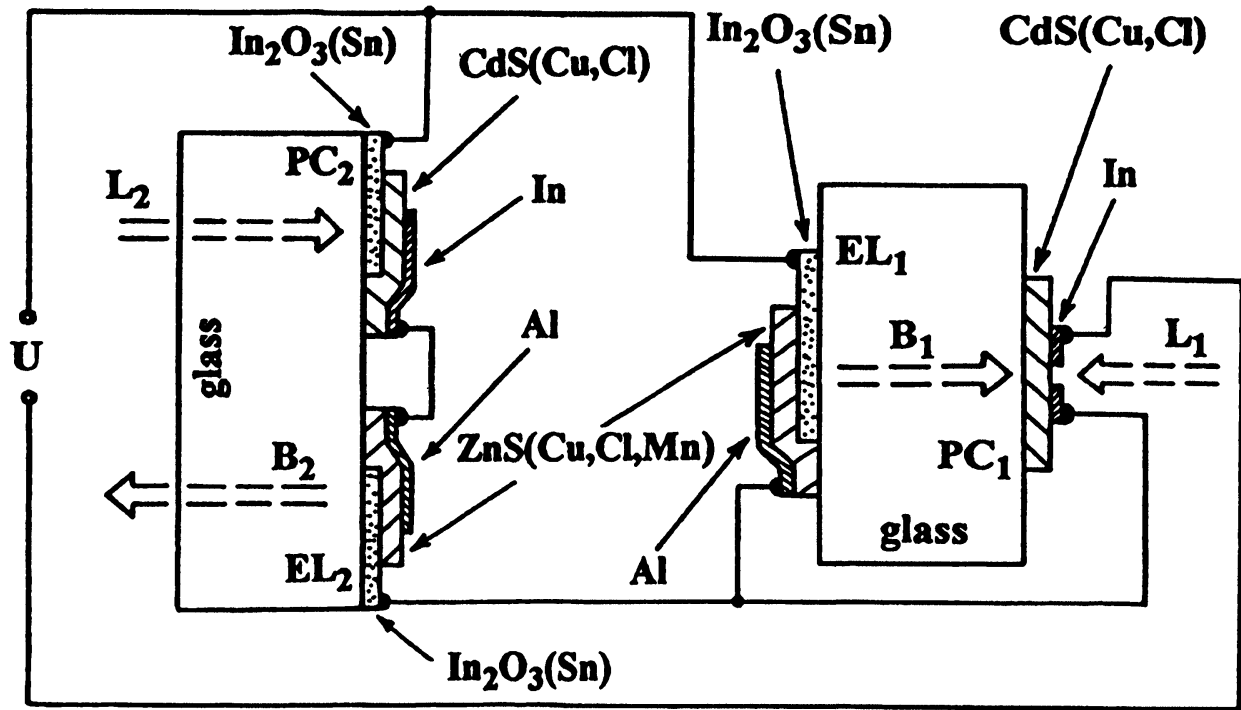

FIGURE 2 Arrangement of the thin film PC-EL systems of an optoelectronic memory element.

manganese-doped $\mathrm{ZnS}^{10}$. The lower transparent conducting electrode was tindoped $\mathrm{In}_{2} \mathrm{O}_{3}$ on a glass substrate, while the upper electrode was a vacuumevaporated thin aluminum film.

The elements $\mathrm{PC}_{1}$ and $\mathrm{PC}_{2}$ as well as $\mathrm{EL}_{1}$ and $\mathrm{EL}_{2}$ were prepared in the same technological processes, to ensure the same values of their parameters.

The experimental values of the parameters of the photoconductive element and electroluminescent cell were found to be as follows:

$\mathrm{C}_{\mathrm{EL} 1}=\mathrm{C}_{\mathrm{EL} 2}=3 \times 10^{-9} \mathrm{~F}$

$\mathrm{G}_{01}=\mathrm{G}_{02}=7 \times 10^{-9} \Omega^{-1}$

$\tau_{1}=\tau_{2}=0.6 \times 10^{-3} s$

$a_{1}=a_{2}=8.3 \times 10^{-4} \Omega^{-1} \cdot 1 x^{-1} \cdot s^{-1}$

$b_{1}=b_{2}=17 \mathrm{~V}^{1 / 2}$

$\mathrm{B}_{01}=\mathrm{B}_{02}=200 \mathrm{~cd} \cdot \mathrm{m}^{-2}$

$\gamma_{1}=\gamma_{2}=600 \mathrm{~s}^{-1}$

and

$\beta=0.5 \mathrm{~lx} \cdot \mathrm{m}^{2} \cdot \mathrm{cd}^{-1}$.

Dynamic characteristics of an optoelectronic memory system were measured for supplying this system with voltage of amplitudes: 280, 420, and $560 \mathrm{~V}$ and for frequencies $100,200,500$, and $1000 \mathrm{~Hz}$.

In Fig. 3, the dependences of luminance $B_{1}$ on the time for supplying voltage of amplitude $420 \mathrm{~V}$ and frequencies $100,200,500$, and $1000 \mathrm{~Hz}$ and in Fig. 4 the dependence of luminance $B_{2}$ on the time for the same parameters of supplying voltage are presented. 

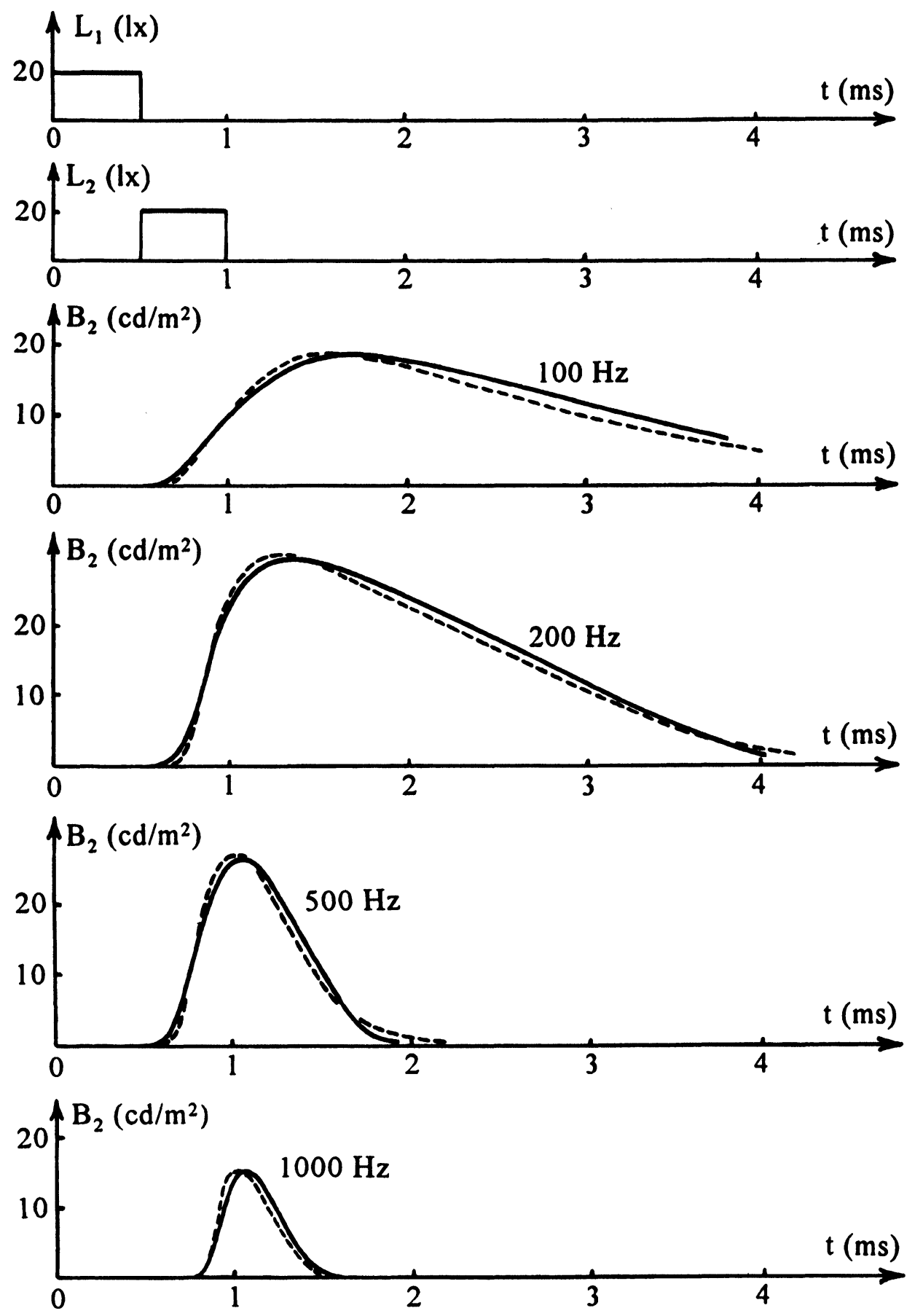

FIGURE 4 Dependences of luminance $B_{2}$ on time for $U_{0} 420 \mathrm{~V}$ and frequencies 100, 200, 500 and $1000 \mathrm{~Hz}$. - - measured values, --- calculated values. 
In Fig. 5 the time dependences of luminance $B_{1}$ and $B_{2}$ for frequency $500 \mathrm{~Hz}$ and three values of supplying voltage amplitude $(280,420$, and $560 \mathrm{~V})$ are presented.

\section{CONCLUSIONS}

Both the analysis of the proposed theoretical model and the measurements have shown that the maximum values of luminances $B_{1}$ and $B_{2}$ depend on the amplitude as well as on the frequency of voltage supplying the investigated memory system. As can be seen from Figs 3 and 4, maximum values of luminances $B_{1}$ and $B_{2}$ for frequencies 200 and $500 \mathrm{~Hz}$ are higher than for frequencies 100 and $1000 \mathrm{~Hz}$. From this fact, the limiting value of the optical feedback coefficient $\beta_{\text {LIM }}$ depends on the
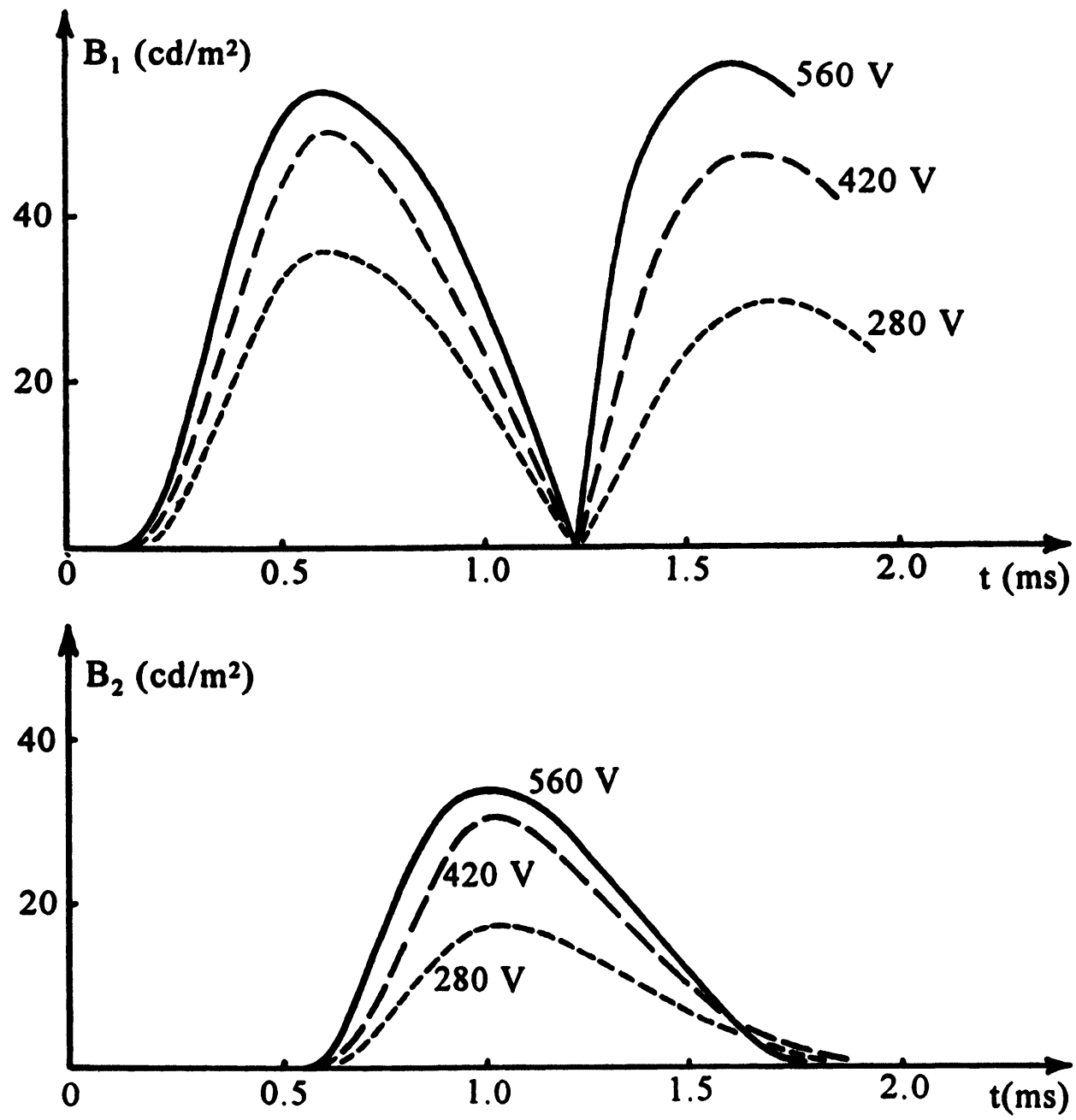

FIGURE 5 Dependences of luminances $B_{1}$ and $B_{2}$ on time for frequency $500 \mathrm{~Hz}$ and $U_{0} 280,420$ and $560 \mathrm{~V}$. 
frequency and amplitude of the supplying voltage and reaches a minimum for the frequency of about $300 \mathrm{~Hz}^{11}$. Thereby the conditions of optical feedback for frequencies 200 and $500 \mathrm{~Hz}$ in the investigated system are more advantageous than for frequencies 100 and $1000 \mathrm{~Hz}$.

The increase of the amplitude of the supplying voltage results also in an increase of the maximum luminances $B_{1}$ and $B_{2}$ (Fig. 5). Moreover, one observes an earlier appearance of the maximum for higher amplitudes of supplying voltage. It results also from the dependence of $\beta_{\text {LIM }}$ coefficient on the amplitude of supplying voltage.

All measured dynamic characteristics for the thin film optoelectronic memory system showed a good conformity with the characteristics calculated on the base of the proposed theoretical model.

\section{REFERENCES}

1. T.I. Coutts (ed.), Active and Passive Thin Film Devices, Academic Press, New York 1978.

2. H.K. Henisch, Electroluminescence, Pergamon Press, Oxford 1962.

3. L.L. Kazmerski (ed.), Polycrystalline and Amorphous Thin Films and Devices, Academic Press, New York 1980.

4. Z. Szepesi, Thin film PC-EL sandwich type image intensifiers, Thin Solid Films 13, 397 (1972).

5. Z. Porada, Thin Solid Films 109, 213 (1983).

6. Z. Porada and E. Schabowska-Osiowska, Active Passive Elec.Comp. 13, 151 (1988).

7. Z. Porada, E. Schabowska-Osiowska, Thin Solid Films 164, 411 (1988).

8. G.F. Alfrey and J. B. Taylor, Br. J. Appl. Phys., 4, 44S (1955).

9. Z. Porada and E. Schabowska, Thin Solid Films 66, L55 (1980).

10. Z. Porada and E. Schabowska, J. Lumin. 21, 129 (980).

11. Z. Porada, Thin Solid Films 109, 213 (1983). 

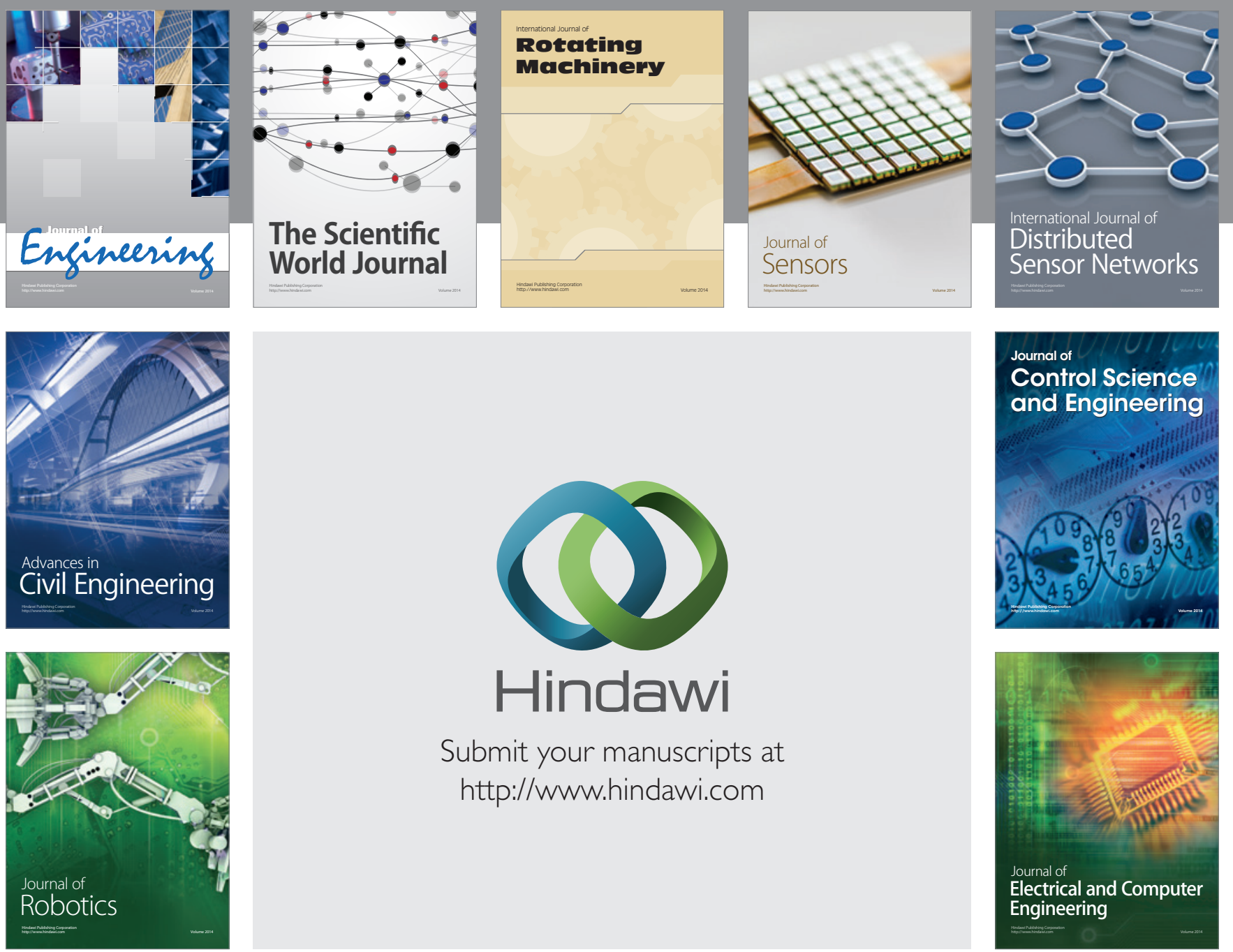

Submit your manuscripts at

http://www.hindawi.com
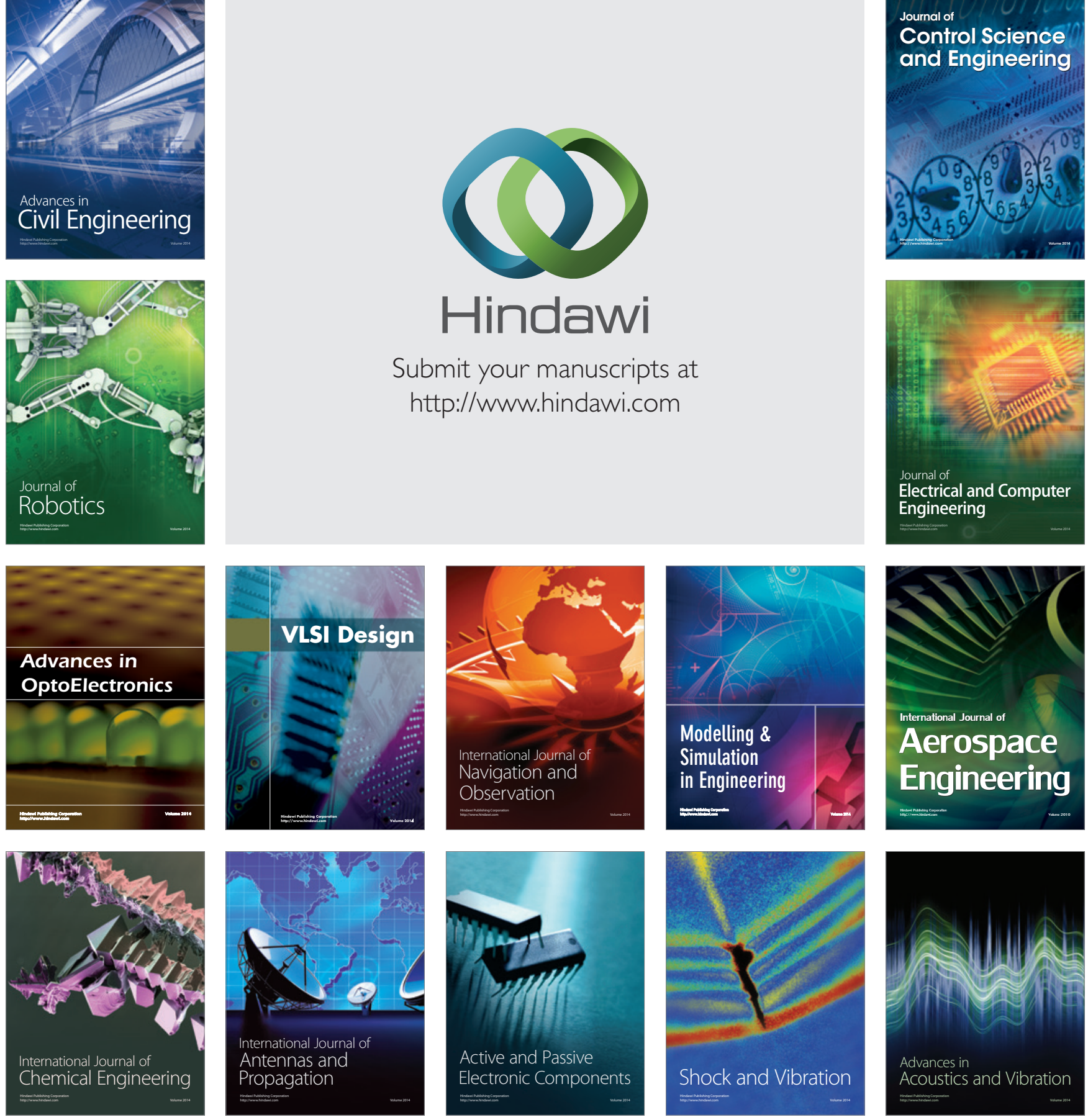